\title{
The Management of Student Cadres in Colleges and Universities Based on Human Resources Theory*
}

\author{
Jun Yang \\ School of Computer Science Technology \\ Shandong Technology and Business University \\ Yantai, China 264005
}

\begin{abstract}
The human resources management of student cadres is a systematic project. The management tasks are arduous and complicated, of which the most important ones are training and motivation. College counselors should establish a sound incentive mechanism based on student cadres and develop appropriate training, to transform the management model of student cadres into a "people-oriented" human resources management model according to the cultural construction of campus so as to realize the optimum sustainable development of student service.
\end{abstract}

Keywords-human resources; management theory; student cadre; college counselors

\section{INTRODUCTION}

The college education has students as its object, and also includes the elements such as people, things, events, time and space, as well as information. Among them, the management of student cadres is an important part, and student cadres are the core human resources of student service, so the maximized mobilization and development of their enthusiasm and their potentials are the important tasks of college counselors in education. For the management of student cadres, there generally are two modes, namely, personnel management mode and human resource management mode. The personnel management mode is mainly based on "things", to mainly deal with administrative affairs of files and recording and attendance; while the human resources management is a series of scientific and rational updating, allocation, use, development, and motivation of student cadre resources to achieve the target in a certain period.

The performance formula proposed by American organizational behaviorist Campbell is: performance $=\mathrm{f}$ (subjective and objective conditions). Assuming that objective conditions are met, only subjective conditions are designed and the key factors, namely competence and motivation, are selected. Therefore, the performance formula becomes: performance $=$ capability $\times$ incentive. According to Porter Lawler's process motivation theory, performance is mainly determined by the human effort due to incentives, but at the

*This paper is the research results of "Yang Jun Counselor Studio" of Shandong Shandong Technology and Business University in 2018; the research result of the "Construction of Student Cadre Assessment System Based on Competency" of the Shandong Provincial College Student Education and Management Research Project in 2017., Project No. $<2017$ B030>. same time, it is also affected by the specific abilities of him to complete the job and his understanding of the job. Training and improvement of skills and ability are the fundamental ways. Incentive measures are the key to improving the staff's working standards. Therefore, in order to improve the performance of student cadres, the two most important tasks are training and motivation of student cadres. At the same time it is necessary to improve the sense of responsibility, pride, honour, and belonging of student cadres by forming the organizational culture of the campus and strengthening professional ethics training, so that the effect of managing student cadres gets improved.

\section{To ESTABLISH A SOUND INCENTIVE MECHANISM}

The right incentive is the key to management. James, a professor of management at Harvard University in the United States, said: "If there is no incentive, a person's ability can only be played by $20 \%-30 \%$; if he is motivated, the person's ability can be played by $80 \%$ - 90\%." The human resources development and management of student cadres are mainly purposed at the two aspects: first, the human resource allocation must be small-numbered but highly-trained and efficient so as to obtain the maximum use value of human resources; second, we must increase student cadres' enthusiasm for work and exert their maximum subjective initiative. At present, the following content should be considered for the motivation of student cadres:

\section{A. To Fully Consider the Needs of Student Leaders}

Any incentive process begins with the needs of people, ends with the achievement of goals and satisfaction of needs. Therefore, for implementing correct and effective incentive measures, we must grasp and clearly understand the most urgent needs of student cadres. College counselors should first find out the needs of the student cadres at different levels. For example, some student cadres have not done management, and they want to "do a good job" but are afraid of mistakes, for which the counselors should do a good guide and help them complete first few "leadership missions" and further make them set up confidence in their work; for some student cadres who have served the class committee for several years, we should satisfy their mindset that require to be accepted in the new environment so we can appoint the appropriately complex work to them to make them have a new sense of honor and of 
innovation. On this basis, we should distinguish between reasonable and unreasonable needs at different levels, and distinguish between the reasonable needs that can be met and that cannot be satisfied temporarily. For the reasonable needs that can be met, we should timely take measures to satisfy them. If the reasonable needs of the student cadre cannot be satisfied and the counselors emphasize the enthusiasm, their enthusiasm will not be unsustainable and long-lasting, and their ability and wisdom will not be fully played. That is, college counselors must find the right incentives and take appropriate measures to meet different levels of needs so as to guide and control the behavior of student cadres.

\section{B. To Link the Rewards with Performance}

The student cadres who achieve specific goals and make outstanding contributions should be given timely and adequate rewards, including comprehensive assessment point bonus, party school training, position promotion, and honor ratings. Scientific and reasonable performance evaluation is the prerequisite for rewards. If counselors make an unreasonable personnel allocation and work quotas, only focusing on the quantity of work, regardless of the quality of work, or make formalism of assessment and carry out equalitarianism of honors and rewards, and then they will seriously dampen the work enthusiasm of the busy and able workers.

\section{Incentives Must Be Open, Fair and Just}

The obvious dedication of student cadres in experience, ability, and effort should be reflected in their income, duties and other gains. An ideal incentive mechanism should enable student cadres to feel equal in their efforts and income. In order to achieve fairness in the encouragement of student cadres, the distribution standards must be fair, and the distribution procedures must be reasonable. There are many factors that affect people's understanding of the distribution standards and procedural fairness, and the most important is the transparency and openness in the selection of standards and the establishment of procedures, that is, this process must be democratized. Counselors should allow student cadres to personally participate in the formulation of the distribution system, and only when they feel that they have a greater say in the distribution process and think that the procedures are beneficial to them, will they consider it fair. Through a comprehensive view of the inequitable phenomena in assessments and evaluation, we find it is resulted from the lack of scientific assessment standards and management systems. Therefore, the establishment of a sound scientific assessment mechanism and the consolidation of scientific management are the important way to eliminate inequities.

\section{TO IMPROVE THE WORK LEVEL OF STUDENT CADRES THROUGH TRAINING}

Training is a guarantee for the continuous improvement of student cadres and an important impetus for the development of student work. In the colleges and universities, for student cadres, as the "administrators" in certain fields, the continuing education and continuous learning are particularly important. For counselors, on the one hand, they must find ways to increase training, and on the other hand, they must improve the effectiveness and level of training. Concretely, to improve the effectiveness of student cadre training, we should pay attention to the followings:

\section{A. To Make an Analysis of Training Needs of Student Cadres Before Training}

The level of training effectiveness and the establishment of training program are based on the analysis of training needs. An analysis of training needs, is first to make clear the overall situation of work development, such as the problems generally exist among student cadres, and which problems can indeed be solved through the education and training of student cadres; second is to make clear the conditions of student cadres, which student cadres really need a training during the work process, and what types and content of training are required for them. The analysis of training needs is the key and prerequisite for success of instructor in training. Therefore, it must be included in the counselors' training management system. Generally speaking, it is necessary to analyze the four items of "who needs training, what type of training is needed, who need training, and what training can achieve the desired results", and by these, we can make a training plan accordingly.

\section{B. To Link Training with Promotion and Important Duty Arrangement}

Training is a continuous process and should be closely linked to the personal development of student cadres and the development plan of the entire student service strategy. The core goal of student cadre training is to achieve the common development of student cadres and the entire student work.

\section{To Guide Student Cadres to Make a Team Learning}

Different from the methods of advanced studies and offthe-job training, team learning is an empirical learning method, and it emphasizes the communication, enlightenment, and mutual imitation of tacit knowledge such as experience, skills and tips among team members. Team learning emphasizes learning here and there from time to time, and requires members to overcome their self-defense mentality, to learn from each other, communicate with each other, inspire each other, and jointly think about solutions to problems so as to achieve the team goals. Therefore, counselors should take various measures to daringly encourage student cadres to conduct team learning and promote their exchanges on work.

\section{TO SHAPE THE ORganizATIONAL CUlture OF CAMPUS}

When mastering the two basic measures of motivation and training, we also greatly shape the organizational culture of campus and actively promote the course of human resources management for student cadres. The social psychologist Lie Wen once put out that human behavior depended not only on the subjective factors of individuals, but also on the environmental conditions in which they are, and a good environment is conducive to inspiration, restraint, regulation, and guidance of human behavior.

For student cadres, environmental conditions refer to the internal environment of campus organization culture and the big social development background, of which campus 
organization culture is the main influence factor. Campus organization culture generally includes positive values and sound rules and regulations. Among these, positive values are the core and soul of organizational culture, and a series of rules and regulations and various forms of activities all are concrete expressions and implementation of values.

For reasonable human resources management for student cadres, college administrators must establish relatively supporting values, mainly to promote the sense of loyalty of student cadres for schools, cultivate student cadres' pride in student unions and class organizations, to make them acknowledge the difference among personal abilities and the differences resulted from their differences of abilities, foster their collaboration and solidarity, encourage their innovation, promote the education ethics, and encourage student cadres to make a continuous learning. Through the establishment of these values, an atmosphere of respecting people, understanding people, caring people, and trusting people will be inevitably developed in the campus. On the one hand, this "people-oriented" organizational culture will guide student cadres to establish a correct education concept, strengthen the professional ethics of student cadres and enhance the rally power; on the other hand, as an internal drive, this will also enable student cadres to make self-motivation and restraint and increase the overall vigor and fighting capacity.

\section{CONCLUSION}

In short, college counselors should take student cadres as the basis, regard student cadres as a valuable fortune, pay attention to satisfaction of the reasonable needs of student cadres, and place the core of management on the mobilization of enthusiasm and initiative of student cadres. Through the establishment of a sound incentive mechanism, appropriate training, and construction of campus organization culture, the management of student cadres will transform from a personnel management mode to a "people-oriented" human resource management mode, so as to achieve a sound and sustainable development of student service.

\section{REFERENCES}

[1] Peter Drucker. Management Challenges in the 21st Century [J]. Business Management, 2010(4). 彼得 - 德鲁克.21 世纪的管理挑战 [J]. 企业管理, 2010(4).

[2] Huang Peilun. Organizational Behavior[M]. Guangzhou: South China University of Technology Press, 2001. 黄培伦. 组织行为学[M].广州:华 南理工大学出版社, 2001 .

[3] Wu Zhihong. New Educational Management [M]. Shanghai: East China Normal University Press, 2010. 吴志宏.新编教育管理学[M].上海:华 东师范大学出版社, 2010 . 